\title{
Factors for Development of the Educational and Professional Qualification Profile of the Human Resources in the Machine Building Sector in Bulgaria
}

\author{
Mariana Petrova ${ }^{1,}$, , Milena Tepavicharova ${ }^{2}$ and Lyudmila Dikova $^{2}$ \\ ${ }^{1}$ St. Cyril and St. Methodius University of Veliko Tarnovo, Veliko Tarnovo, Bulgaria \\ ${ }^{2}$ Higher School of Security and Economics - Plovdiv, 13 Kuklensko Shose Blvd., 4004 Plovdiv
}

\begin{abstract}
Along with cost optimization, the main reserve is the use of the workforce. Development opportunities depend not only on the level of equipment and technology, but also on the added value of the participants managers, specialists, workers. The fundamental understanding should be that the workforce is not only a basic production factor, but also an important source of income for the enterprise. The purpose of this article is to analyse the main factors of the management of professional development and human resources qualification, influencing the production and economic results in the machine-building sector. The article is structured into two main sections. The first includes an analysis of the factors of the management of professional development and the qualification of the human resources, by examining their interrelations and links with the economic results by types of enterprises in the machinebuilding sector. The second section presents a model of the factors which are particularly important for achieving high economic results.
\end{abstract}

\section{Introduction}

The 1990s witnessed significant changes in the structure of the Bulgarian economy by sector. Following the accelerated industrialization of the country in the 1990s, the machinebuilding industry suffered almost a continuous and far-reaching decline in both the relative weight and the volume of production. Under the influence of the economic situation during this period, there were significant changes in the employment too - the share of the employees in the machine-building enterprises decreased by about a quarter [1]. These sudden and significant structural alterations have shaped both the substantial general imbalance in the labor market and the large inadequacies in the educational and qualification aspect [2].

With the stabilization of the economy and the structural changes in it since 2000, the conditions for a fuller use of the human resources have been slowly improving. The significant structural modifications, however, are imposing new requirements on the

\footnotetext{
*Corresponding author: m.petrova@ts.uni-vt.bg
} 
knowledge and skills of the workers [3]. Acquiring, restoring and enhancing new knowledge and skills requires time and resources.

The resulting crisis in the European and other markets led to a sharp contraction of production (especially in 2009), resulting in quantitative and structural changes in the workforce in the machine-building sector. This has influenced the effectiveness of business operations [4].

The complex economic situation in the EU, and its repercussions in our country, outline even more sharply the main problems in the development of the machine-building sector:

- in terms of finance and economics: slow and low growth of capital, insufficient expansion of the investment potential and as a result - lack of conditions for effective and economically more significant growth;

- inconsistency in the production and the technological potential of the requirements for the production of high-tech scientifically demanding products;

- continuing reduction of the companies' ability to influence on key production factors, in particular on the quality of the workforce and enterprise innovation $[5,6]$.

Under these conditions, the use of internal reserves becomes an important resource to sustain production [7]. Along with cost optimization, the main reserve is the use of the workforce. Development opportunities depend not only on the level of equipment and technology, but also on the added value of the participants - managers, specialists, workers. The fundamental understanding should be that the workforce is not only a basic production factor, but also an important source of income for the enterprise $[8,9]$.

The purpose of this article is to analyze the main factors of the management of professional development and human resources qualification, influencing the production and economic results in the machine-building sector.

The article is structured into two main sections. The first includes an analysis of the factors of the management of professional development and the qualification of the human resources, by examining their interrelations and links with the economic results by types of enterprises in the machine-building sector. The second section presents a model of the factors which are particularly important for achieving high economic results.

\section{Materials and methods}

68 enterprises were surveyed during investigation of the factors for the development of the educational and professional qualification profile of the human resources in the machinebuilding sector. Their selection is based on their positive economic performance, or realized profit for the period under focus. The effect and interaction of the main factors of professional development and human resource qualification affecting the size of profit in the machine-building enterprises is investigated using Pearson's correlation analysis. For the purpose of the analysis, the companies are grouped into three groups according to their legal form. The first group includes Sole Traders (SL) enterprises. These are mostly smallsized companies, where most of the production is designated for the local markets. The second and third group include capital companies. These are Sole Proprietor Limited Liability Companies (Ltd.) and Limited Liability Companies (LLC). In these legalorganizational forms, vocational education, qualifications and manufacturing experience are the core factors for achieving good economic performance.

In order to study the state of the educational and professional qualification profile of the human resources, we use factors which reveal in depth the acquired education, the professional experience and the opportunities for improving the professional qualification according to the Labor Code and the internal normative acts of the enterprises in the machine-building sector. (Table 1.) The factors considered are differentiated for the management and the subordinate staff. Under management staff, we will list all managers 
from different levels of management who have the power to take and implement a management decision without necessarily being coordinated with managers from other levels. The subordinate staff includes all employees in the companies who are not in a position to take management decisions, and must necessarily coordinate with the decisionmaker for the particular activity [10].

Table 1. Factors for analysis of the professional development and qualification of the human resources

\begin{tabular}{|c|c|c|c|}
\hline \multicolumn{4}{|c|}{ Educational and professional-qualification profile of managerial staff } \\
\hline $\begin{array}{l}\text { 1.Education } \\
\text { a/ secondary general level; } \\
\text { b/ vocational secondary } \\
\text { education; } \\
\text { c/ higher education - } \\
\text { bachelor's; } \quad \mathrm{d} / \\
\text { higher education - master's; }\end{array}$ & $\begin{array}{l}\text { 2. Professional } \\
\text { experience } \\
\text { a/ up to } 15 \text { yrs.; } \\
\text { b/ from } 16 \text { to } 35 \\
\text { yrs.; } \\
\text { c/ above } 36 \text { yrs. }\end{array}$ & $\begin{array}{l}\text { 3. Professional } \\
\text { specialization } \\
\text { a/ at home; } \\
\text { b/ abroad. }\end{array}$ & $\begin{array}{l}\text { 4. Learning and use of } \\
\text { foreign languages } \\
\text { a/English; } \\
\text { b/French; } \\
\text { c/German; } \\
\text { d/Russian; } \\
\text { e/Other languages }\end{array}$ \\
\hline
\end{tabular}

\begin{tabular}{lc}
\hline \multicolumn{1}{c}{ Educational and professional-qualification profile of subordinate staff } \\
\hline 1. Education & 2. Professional experience \\
a/ elementary educational level; & a/ up to $15 \mathrm{yrs} . ;$ \\
b/ basic educational level; & b/ from 16 to $35 \mathrm{yrs}$; \\
c/ secondary general level; & c/ above $36 \mathrm{yrs}$. \\
d/ vocational secondary education; & \\
e/ higher education & \\
\hline
\end{tabular}

In the second section of the paper we present a model of the factors of the educational and professional qualification profile of the human resources. It addresses these factors, which are particularly important for achieving high economic performance in the machinebuilding enterprises. For the construction of this model, the technique of Path-coefficient analysis is applied. This method combines the possibilities of correlation, regression and structural analysis. This makes it one of the most appropriate methods for studying relationships since the Path Analysis examines not only the direct but also the indirect links between the factors of management of the educational and professional qualification profile of the human resources and the economic performance of the enterprises. In this way, the factors having the strongest impact are evaluated, and the weak ones are eliminated.

The survey covers the period between 2016-2018. The data and information are collected through direct contacts, completing special reports, tables, company documentation, etc. developed for the purpose of the analysis. The data processing SPSS software is used to process the statistical information.

\section{Results and discussion}

\subsection{Analysis of the factors of the professional development and qualification of the human resources, influencing and interacting with the economic results in the machine-building enterprises}

The factors included in the educational and professional qualification profile of the management staff cover the acquired level of education, the improvement of the professional experience and qualification, as well as the training and self-learning opportunities of the managerial staff in the studied companies in the machine-building sector. The analysis of the impact of these factors on the economic performance will help to further build a strategy for subsequent selection, training and human resources development. 
The study of the Education factor reveals that managers with higher education Master's and Bachelor's degrees, have a major influence on the economic performance of the enterprises. /Table 2./ Their significance is evidenced by high correlation coefficients, respectively at Master's degree with $\mathrm{R}=0.734$ at $\alpha=0.01$ and at Bachelor's degree with $\mathrm{R}$ $=0.511$ at $\alpha=0.05$. This demonstrates that a higher level of education for the managers is a prerequisite for achieving positive production-economic results. The significance of this level of education is also confirmed by the types of businesses according to their legal form, as the relation with the capital companies is stronger - at LLC with $\mathrm{R}=0.983$ at $\alpha=$ 0.01 and Ltd. with $\mathrm{R}=0.933$ at $\alpha=0.01$. The other educational levels included in the research do not have a beneficial effect on the economic results of the surveyed enterprises.

Table. 2. Influence of the factors included in the educational and professional qualification profile of the management staff.

\begin{tabular}{lcccc}
\hline $\begin{array}{l}\text { Correlation coefficients } \\
\text { Factors }\end{array}$ & Total & SL & Ltd. & LLC \\
\hline l.Education & & & & \\
a/ secondary general level; & $-0.463^{*}$ & -0.178 & $-0.607^{* *}$ & -0.267 \\
b/ vocational secondary education; & 0.168 & 0.006 & 0.214 & 0.111 \\
c/ higher education - bachelor's; & $0.511^{*}$ & 0.289 & $0.829^{* *}$ & $0.834^{* *}$ \\
d/ higher education - master's; & $0.734^{* *}$ & $0.496^{*}$ & $0.933^{* *}$ & $0.983^{* *}$ \\
2. Professional experience & & & & \\
a/ up to 15 yrs.; & $0.837^{* *}$ & $0.431^{*}$ & $0.786^{* *}$ & $0.839^{* *}$ \\
b/ from 16 to 35 yrs.; & $0.649^{* *}$ & $0.928^{* *}$ & $0.547^{*}$ & $0.617^{* *}$ \\
c/ above 36 yrs. & -0.288 & $-0.783^{* *}$ & $-0.487^{*}$ & 0.031 \\
3. Professional specialization & & & & \\
a/ at home; & $0.411^{*}$ & $0.584^{* *}$ & $0.568^{*}$ & $0.948^{* *}$ \\
b/ abroad. & $0.664^{* *}$ & 0.243 & $0.631^{* *}$ & $0.966^{* *}$ \\
4. Learning and use of foreign languages & & & & \\
a/English; & $0.498^{*}$ & $0.574^{*}$ & $0.604^{* *}$ & $0.834^{* *}$ \\
b/French; & 0.035 & 0.098 & 0.023 & 0.137 \\
c/German; & 0.188 & 0.127 & 0.198 & 0.156 \\
d/Russian; & 0.307 & 0.173 & $0.439^{*}$ & 0.014 \\
e/ otherlanguages. & $0.479^{*}$ & 0.287 & 0.167 & $0.639^{* *}$ \\
\hline Studied firms ,\% & $\mathbf{1 0 0}$ & $\mathbf{4 1}$ & $\mathbf{2 3}$ & $\mathbf{3 6}$ \\
\hline Source: Own
\end{tabular}

Source: Own calculations; ${ }^{*}$ Correlation is significant at the 0.05 level; $* *$ Correlation is significant at the 0.01 level

Professional experience is a factor which takes into account the acquired professional knowledge and skills as well as the possibility of their full application in practice. The present research exhibits that the most significant impact on the positive economic results is provided by the factor Work Experience of the managers of up to 15 years. They show a high correlation coefficient of 0.837 , statistically proven at $\alpha=0.01$. The significance of this group of managers is also observed in the capital companies belonging to the Ltd. group with $\mathrm{R}=0.786$ at $\alpha=0.01$ and in the group of LLC with $\mathrm{R}=0.839$ at $\alpha=0.01$. The correlation of the managers with experience in the work specialty between 16 and 35 years and the realized profit $/ \mathrm{R}=0.649$ for $\alpha=0.01 /$ is also statistically proven. This group of managers has a particularly strong influence on the economic condition of SL with $\mathrm{R}=$ 0.928 at $\alpha=0.01$. The results obtained show that the professional experience is a significant factor only when combined with innovative thinking and application of new techniques and technologies in production.

The professional qualification profile of the managerial staff in the machine building businesses also emphasizes the impact of additional training and career development on the economic situation. In this sense, specialized training in the country and abroad are a powerful tool for the professional development and enhancing of the managers' potential. 
Applying the knowledge gained in practice has a strong impact on achieving high economic performance. In the survey, there is a strong direct correlation between the realized profit and the knowledge of the managers acquired by specializations at home $/ \mathrm{R}=0.411$ at $\alpha=0.05 /$ and abroad $/ R=0.664$ at $\alpha=0.01 /$. The significance of these factors for the economic situation is evidenced by the three types of enterprises according to their legal form.

Specializations abroad are a factor which have a positive impact on the professional development of managers. They also help to better learn foreign languages and make communication more effective among professionals. In this sense, the current study shows a strong interdependence between managers' knowledge and capabilities of using languages and the economic performance of the companies. Of particular importance is the smooth use and communication in English $/ \mathrm{R}=0.498$ at $\alpha=0.05 /$ and other languages $/ \mathrm{R}=0.479$ at $\alpha=0.05 /$. Similar results are also observed in the types of companies according to their legal form. This is a proof that learning and the use of foreign languages is important for achieving positive economic performance. Such knowledge enables easy access to international scientific achievements. This ensures a constant updating of the knowledge and professional development of the managers. The acquisition and application of most contemporary techniques and technologies in manufacturing leads to the achievement of positive economic results in the enterprises of the machine-building sector.

The practical application of "good" manufacturing practices, the implementation of European standards and the use of modern techniques and technologies are only possible with well-chosen subordinate staff with the necessary level of education, qualification and professional experience. It is therefore of particular importance to examine the impact of the educational and professional qualification profile of the subordinate staff on the manufacturing and economic situation of the machine-building companies.

The research of the Education factor shows a very strong direct proportional interdependence between the subordinate staff with secondary special education and the realized profit. This factor has a very high correlation coefficient of 0.843 at $\alpha=0.01$. /Table 3./ Its significance is demonstrated in all types of enterprises, with the greatest impact being reported for Ltd. with $\mathrm{R}=0.899$ at $\alpha=0.01$. The results are similar in other types of enterprises - for SL with $\mathrm{R}=0.659$ at $\alpha=0.01$ and for $\mathrm{LLC}$ with $\mathrm{R}=0.769$ at $\alpha=$ 0.01 .

Another fundamental factor for achieving positive economic results in the surveyed enterprises is the subordinate staff with higher education $/ \mathrm{R}=0.611$ at $\mathrm{a}=0.01 /$. In this respect, its strong influence in the enterprises is statistically proven at Ltd. - $\mathrm{R}=0.646$ at $\alpha$ $=0.01$, as in the case of LLC $-\mathrm{R}=0.657$ at $\alpha=0,01$. The other studied levels of education have little impact on the realization of positive economic results, as in the case of the employees with a primary level of education, even a negative correlation is reported. Such negative impact on profit is also exercised by those with primary and elementary education in the capital companies. From the data presented, it is evident that the high level of education of the subordinate staff is a necessary condition for achieving high economic results. A well-trained and knowledge-savvy worker is more receptive to and applies innovation, which leads to a faster and better execution of the assigned production tasks.

In the subordinate staff, the study also covered the impact of the work experience gained on the achievement of positive economic performance. The data reveal a strong, statistically proven correlation between the realized profit and the subordinate personnel with work experience in the specialty of up to 15 years $/ \mathrm{R}=0.606$ for $\alpha=0.01 /$ and the ones with professional experience from 16 to 35 years $/ \mathrm{R}=0.599$ at $\alpha=0.01$. Similar data are reported for all three types of enterprises according to their legal form. This shows that the quality of the practical implementation of management decisions and the achievement 
of good production-economic results is not always directly related to the length of the acquired professional experience.

Table 3. Influence of the factors included in the educational and professional qualification profile of the subordinate staff

\begin{tabular}{lcccc}
\hline Correlation coefficients Factors & Total & SL & Ltd. & LLC \\
\hline 1.Education & & & & \\
a/ elementary educational level; & -0.094 & 0.034 & -0.009 & -0.066 \\
b/ basic educational level; & 0.036 & 0.216 & -0.001 & -0.129 \\
c/ secondary general level; & 0.334 & 0.401 & 0.227 & 0.376 \\
d/ vocational secondary education; & $0.843^{* *}$ & $0.659^{* *}$ & $0.899^{* *}$ & $0.769^{* *}$ \\
e/ higher education & $0.611^{* *}$ & 0.416 & $0.646^{* *}$ & $0.657^{* *}$ \\
2. Professional experience & & & & \\
a/ up to 15 yrs.; & $0.606^{* *}$ & $0.637^{* *}$ & $0.453^{*}$ & $0.518^{*}$ \\
b/ from 16 to 35 yrs.; & $0.599^{* *}$ & 0.326 & $0.628^{* *}$ & $0.664^{* *}$ \\
c/ above 36 yrs. & 0.217 & 0.306 & 0.217 & 0.193 \\
\hline Studied firms ,\% & $\mathbf{1 0 0}$ & $\mathbf{4 1}$ & $\mathbf{2 3}$ & $\mathbf{3 6}$ \\
\hline
\end{tabular}

Source: Own calculations; ${ }^{*}$ Correlation is significant at the 0.05 level; ${ }^{*}$ Correlation is significant at the 0.01 level

The current analysis shows the correlation and the impact of the factors of the educational and professional qualification profile of the human resources on the economic condition of the businesses from the machine-building sector in Bulgaria. On the basis of this analysis, a combination of factors which are most influential on the economic performance can be proposed.

\subsection{A model of the factors of the professional development and qualification of the human resources, influencing directly or indirectly the high economic performance in the machine-building enterprises}

The method of Path analysis is applied to study the impact of both the direct and the indirect correlations of the factors of the educational and professional qualification profile of the human resources on the economic condition of the machine-building enterprises. This method evaluates only those factors which have the fullest impact on the economic performance and the weak ones are eliminated. The results obtained from the Path analysis of the management personnel are shown in Table 4.

Table 4. Direct and indirect effect of the factors included in the educational and professional qualification profile of the management staff

\begin{tabular}{lcc}
\hline $\begin{array}{l}\text { Path-coefficients } \\
\text { Factors }\end{array}$ & Direct effect & Indirect effect \\
\hline 1. Professional experience up to 15 yrs.; & -0.133 & 0.970 \\
2. Professional experience from 16 to 35 yrs.; & 0.496 & 0.153 \\
3. Higher education - master's; & 0.494 & 0.240 \\
4. Higher education - bachelor's; & 0.779 & -0.268 \\
5. Professional specialization at home; & 0.636 & -0.225 \\
6. Professional specialization abroad; & 0.469 & 0.195 \\
7. English proficiency & 0.326 & 0.172 \\
8. Proficiency in Russian language & -0.266 & 0.573 \\
9. Proficiency in other languages & 0.628 & -0.149 \\
\hline
\end{tabular}

Proficiency in other languages

The information in the table reveal that some of the factors in the management staff have a positive direct and indirect impact on the economic situation of the enterprises. Such 
factors are assessed as highly positive. In the studied machine-building companies, these are the factors related to the managers with professional experience of over 16 years, holders of Master's degree, fluent in English and specialized abroad.

The factors relating to the managers with Bachelor's degree who specialize in the country and who manage various foreign languages have a direct positive effect on the economic situation of the enterprises in the machine-building sector. However, the indirect impact of this group of factors on the economic performance is negative.

The third set of factors under which fall the managers with up to 15 years of experience and are fluent in Russian, have a direct negative impact on the economic performance. By contrast, the indirect influence of these factors is highly positive. The indirect effect factor exceeds that of the direct one and the ultimate impact of these factors is also positive.

The Path analysis method is also applied to the subordinate staff. This provides an overall picture of the main and most important factors which directly and/ or indirectly influence the achievement of high economic performance. The results of the Path-analysis performed are presented in Table 5.

Table 5. Direct and indirect effect of the factors included in the educational and professional qualification profile of the subordinate staff

\begin{tabular}{lcc}
\hline $\begin{array}{l}\text { Path-coefficients } \\
\text { Factors }\end{array}$ & Direct effect & Indirect effect \\
\hline 1. Professional experience up to 15 yrs.; & 0.683 & -0.077 \\
2. Professional experience from 16 to 35 yrs.; & 0.423 & 0.176 \\
3. Professional experience above 36 yrs.; & -0.234 & 0.451 \\
4. Secondary general level; & 0.663 & -0.329 \\
5. Vocational secondary education; & 0.627 & 0.216 \\
6. Higher education. & -0.148 & 0.759 \\
\hline
\end{tabular}

Own calculations

From the actual analysis we can conclude that the subordinates with experience between 16 and 35 years in the specialty and having secondary vocational education, have the most influence on the achievement of positive economic results in the machine-building enterprises. They have a positive direct and indirect effect, which makes them strongly positive.

The direct positive impact of the factors related to the subordinate employees with up to 15 years of experience and those with secondary education without a specialty acquired, are somewhat reduced by their negative indirect effect.

The third group, including the factors with direct negative and indirect positive effect, refers to subordinates with higher education and having a professional experience of over 36 years. Although the direct impact of these factors on the economic outcome is negative, the indirect positive impact is stronger, resulting in the ultimate positive effect.

The modeling of the professional development factors and the qualification of the human resources, directly or indirectly influencing the high economic performance, contributes to the development of a comprehensive system of selection, training and professional development of the managerial and subordinate personnel in the mechanical engineering enterprises. (Fig. 1.) 


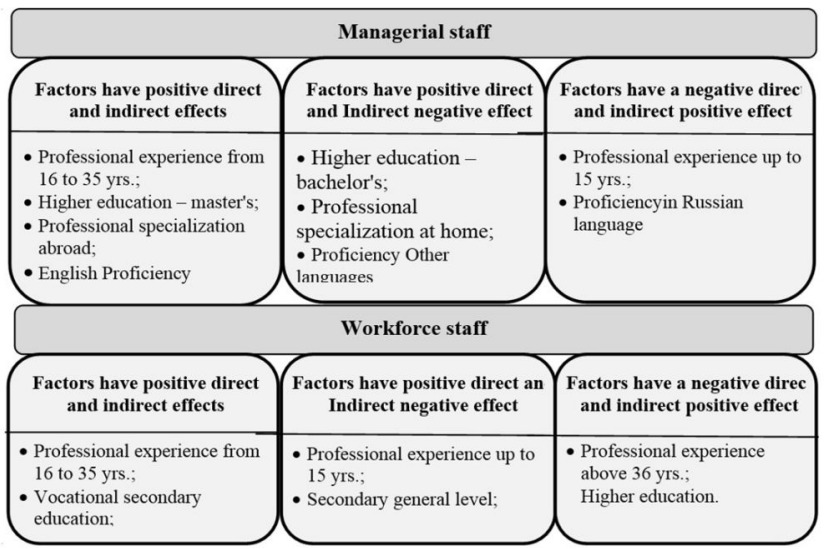

Fig. 1. Model of the factors of the professional development and qualification of the human resources, influencing directly or indirectly the high economic performance in the machine-building enterprises

\section{Conclusions}

As a result of the presented information and the analysis of the influence of the factors of the professional development and the qualification of the human resources on the economic situation of the machine-building businesses, the following more important conclusions can be drawn:

$>$ The competencies and skills of the young professionals are a better prospect of the economic vitality and the enterprise development. The professional experience is a significant factor only when combined with innovative thinking and application of new techniques and technologies in production.

$>$ The high level of education of the managers is a necessary condition for achieving positive production and economic results in the enterprises from the machine-building sector.

$>$ Specializations abroad, as well as the fluent use of foreign languages, are factors which have a strong positive impact on the economic situation of the companies.

$>$ The modeling of the factors of professional development and the qualification of the human resources, which have a positive effect on the economic situation, contribute to the establishment of a comprehensive system of selection, training and professional development of the managerial and

\section{References}

1. V. Nikolova-Alexieva, Journal: PROCEDIA - SOCIAL AND BEHAVIORAL SCIENCES, 62, 1350, (2012)

2. E. Vachkova, International Business School TRANSBUSNESS E, (2007)

3. N. Bencheva, M. Tepavicharova, National Conference "Learning from the crisis lessons learned, recommendations and strategies", 155 (2011)

4. R. Pukala, Economic Annals-XXI, 9:10 67 (2013)

5. R. Pukala, Engineering Management in Production and Services, 8:3, 43 (2016) 
6. I. Todorov, K. Kolev, Project Development and Implementation of an Information System for Assessment of Competences of the Labor Force by Branches and Regions, (2012)

7. M. Petrova, M. Tepavicharova, L. Boykova, E3S Web of Conferences, 41, 04017 (2018)

8. Sv. Labunska, M. Petrova, O. Prokopishyna, Economic Annals - XXI., 165:5-6, (2017)

9. J. Iliev,. Human resource management - the necessary transition from science to the practice of Bulgarian companies (2008)

10. M. Tepavicharova, Scientific Works, 1, 77 (2015) 